\title{
Striking While the Iron Is Hot: Using the Updated PHM Competencies in Time-Variable Training
}

\author{
Benjamin Kinnear, MD, MEd, Nivedita Srinivas, MD², Karen Jerardi, MD, MEd
}

'Department of Pediatrics, Cincinnati Children's Hospital Medical Center, University of Cincinnati College of Medicine, Cincinnati, Ohio; ${ }^{2}$ Department of Pediatrics, Lucile Packard Children's Hospital, Stanford University School of Medicine, Stanford, California.

n July 2020, the revision of The Pediatric Hospital Medicine Core Competencies was published, bringing to fruition three years of meticulous work. ${ }^{1}$ The working group produced 66 chapters outlining the knowledge, skills, and attitudes needed for competent pediatric hospitalist practice. The arrival of these competencies is especially prescient given pediatric hospital medicine's (PHM's) relatively new standing as an American Board of Medical Specialties certified subspecialty, as the competencies can serve as a guide for improvement of fellowship curricula, assessment systems, and faculty development. The competencies also represent an opportunity for PHM to take a bold step forward in the world of graduate medical education (GME) by realizing a key tenet of competency-based medical education (CBME) - competency-based, time-variable training (CBTVT), in which learners train until competence is achieved rather than for a predetermined duration. ${ }^{2,3}$ In this perspective, we describe how medical education in the United States adopted a time-based training paradigm (in which time-in-training is a surrogate for competence), how CBME has brought time-variable training to the fore, and how PHM has an opportunity to be on the leading edge of education innovation.

\section{TIME-BASED TRAINING IN THE UNITED STATES}

In the 1800s, during the time of the "Wild West," medical education in the United States matched this moniker. There was little standardization across the multiple training pathways to become a practicing physician, including apprenticeships, lecture series, and university courses. ${ }^{4}$ Predictably, this led to significant heterogeneity in the quality of medical care that a patient of the day received. This problem became clearer as Americans traveled to Europe and witnessed more structured and rigorous training programs, only to return to the comparatively poor state of medical education back home. ${ }^{5}$ There was a clear need for curricular standardization.

In 1876, the American Medical College Association (which later became the Association of American Medical Colleges

\footnotetext{
*Corresponding Author: Benjamin Kinnear, MD, MEd;
}

Email: kinneabn@ucmail.uc.edu; Telephone: 314-541-4667;

Twitter: @Midwest_MedPeds.

Published online first March 17, 2021.

Received: December 26, 2020; Revised: February 12, 2021;

Accepted: February 16, 2021

(C) 2021 Society of Hospital Medicine DOI 10.12788/jhm.3611
[AAMC]) was founded to meet this need, and in 1905 the Association adopted a set of minimum standards for medical training that included the now-familiar two years of basic sciences and two years of clinical training. ${ }^{6}$ Two subsequent national surveys in the United States were commissioned to evaluate whether medical schools met this new standard, with both surveys finding that roughly half of existing programs passed muster., As a result, nearly half of US medical schools had closed by 1920 in a crusade to standardize curricula and produce competent physicians. By the time the American Medical Association established initial standards for internship (an archetype of GME), ${ }^{4}$ time-based medical training was the dominant paradigm. This historical perspective highlights the rationale for standardization of education processes and curricula, particularly in terms of accountability to the American public. But heralded by the 1978 landmark paper by McGaghie et al, ${ }^{9}$ the paradigm began to shift in the late twentieth century from a focus on the process of physician training to outcomes.

\section{CBME AND TIME VARIABILITY}

In contrast to the process-focused model of the early 1900s, CBME starts by identifying patient and healthcare system needs, defining competencies required to meet those needs, and then designing curricular and assessment processes to help learners achieve those competencies. ${ }^{2}$ This outcomes-based approach grew as a response to calls for greater accountability to the public due to evidence that some graduates were unprepared for unsupervised practice, raising concerns that strictly time-based training was no longer defensible. ${ }^{10} \mathrm{CBME}$ aims to mitigate these concerns by starting with desired outcomes of training and working backward to ensure those outcomes are met.

While many programs have attempted to implement CBME, most still rely heavily on time-in-training to determine competence. Learners participate in structured curricula and, unless they are extreme outliers, are deemed ready for unsupervised practice after a predetermined duration. This model presumes that competence and time are related in a fixed, predictable manner and that learners gain competence at a uniform rate. However, learners do not, in fact, progress uniformly. A study by Schumacher et al ${ }^{11}$ involving 23 pediatric residency programs showed significant interlearner variability in rates of entrustment (used as a surrogate for competence), leading the authors to call for time-variable training in GME. Significant interlearner variation in rates of competence attainment have been shown in other specialties as well. ${ }^{12}$ As more CBME studies on training 
outcomes emerge, the evidence is mounting that not all learners need the same duration of training to become competent providers. Time-in-training and competence attainment are not related in a fixed manner. As Dr Jason ${ }^{13}$ wrote in 1969, "By making time a constant, we make achievement a variable." Variable achievement (competence, outcomes) was the very driver for medical education's shift to a competency-based approach. If variable competence was not acceptable then, why should it be now? The goal of CBTVT is not shorter training, but rather flexible, individualized training both in terms of content and duration. While this also means some learners may need to extend their training, this should already be part of GME programs that are required to have remediation policies for learners who are not progressing as expected.

\section{AN OPPORTUNITY FOR PHM}

Time variability is an oft-cited tenet of $\mathrm{CBME}_{1}^{2,3}$ but one that is being piloted by relatively few programs in the United States, mostly in undergraduate medical education (UME). ${ }^{14-16}$ The Education in Pediatrics Across the Continuum (EPAC), a consortium consisting of four institutions piloting CBTVT in UME, ${ }^{14}$ has shown early evidence of feasibility ${ }^{17}$ and that UME graduates from CBTVT programs enter residency with levels of competence similar to those of graduates of traditional time-based programs. ${ }^{18}$ We believe that PHM can take a step toward truly realizing CBME by implementing CBTVT in fellowship programs.

There are multiple reasons why this is an opportune time for PHM fellowships to consider CBTVT. First, PHM is a relatively new board-certified subspecialty with a recently revised set of core competencies ${ }^{1}$ that are likely to catalyze programmatic innovation. A key step in change management is building on previous efforts to generate more change. ${ }^{19}$ Programs can leverage the momentum from current and impending change initiatives to innovate and implement CBTVT. Second, the revised $\mathrm{PHM}$ competencies provide the first crucial step in implementing a CBME program by defining desired training outcomes necessary to deliver high-quality patient care. With PHM competencies now well defined, programs can focus on developing programs of assessment and corresponding faculty development, which can help deliver valid, defensible decisions about fellow competence.

Finally, PHM has a workforce that can support CBTVT. A major barrier to time-variable training in GME is the need for trainees-as-workforce. In many GME programs, residents and fellows provide a relatively inexpensive, renewable workforce. Trainees' clinical rotations are often scheduled up to 1 year in advance to ensure care teams are fully staffed, particularly in the inpatient setting, creating a system where flexibility in training is impossible without creating gaps in clinical coverage. However, many PHM fellowships do not completely rely on fellows to cover clinical service lines. PHM fellows spend 32 weeks over 2 years in core clinical rotations with faculty supervision, in accordance with the Accreditation Council for Graduate Medical Education program requirements, both for 2- and 3-year programs. Some CBME experts estimate (based on previous and ongoing CBTVT pilots) that training duration is likely to vary by roughly $20 \%$ from current time-based practices when CBTVT is initially implemented. ${ }^{20}$ Thus, only a small number of clinical service weeks are likely to be affected. If a fellow were deemed ready for unsupervised practice before finishing 2 years of fellowship in a CBTVT program, the corresponding faculty supervisor could use the time previously assigned for supervision to pursue other priorities, such as education, scholarship, or quality improvement. Why provide supervision if a clinical competency committee has deemed a fellow ready for unsupervised practice? Some level of observation and formative feedback could continue, but full supervision would be redundant and unnecessary. CBTVT would allow for some fellows to experience the uncertainty that comes with unsupervised decision-making while still in an environment with trusted fellowship mentors and advisors.

\section{STEPS TOWARD CHANGE}

PHM fellowship programs likely cannot flip a switch to "turn on" CBTVT immediately, but they can take steps toward making the transition. Validity, or defensibility of decisions, will be crucial for assessment in CBTVT systems. Programs will need to develop robust assessment systems that collect myriad data to answer the question, "When is this learner competent to deliver high-quality care without supervision?" Programs can align assessment instruments, faculty-development initiatives, and clinical competency committee (CCC) processes with the 2020 PHM competencies to provide a defensible answer. Program leaders should then seek validity evidence, either in existing literature or through novel scholarly initiatives, to support these summative decisions. Engaging all fellowship stakeholders in transitions to CBTVT will be important and should include fellows, program directors, CCC members, clinical leadership, and members from accrediting and credentialing bodies.

\section{CONCLUSION}

As fellowship programs review and revise curricula and assessment systems around the updated PHM core competencies, they should also consider what changes are necessary to implement CBTVT. Time variability is not a novelty but, rather, is a corollary to the outcomes-based approach of CBME. PHM fellowships should strike while the iron is hot and build on current change initiatives prompted by the growth of our specialty to be leaders in CBTVT.

Disclosure: The authors have nothing to disclose.

Funding: Dr Kinnear has received funding from the Josiah Macy Jr. Foundation for education innovation to pilot competency-based time-variable training at the University of Cincinnati's internal medicine residency program.

\section{References}

1. Maniscalco J, Gage S, Sofia Teferi M, Fisher ES. The Pediatric Hospital Medicine Core Competencies: 2020 Revision. J Hosp Med. 2020;15(7):389-394. https://doi.org/10.12788/jhm.3391

2. Frank JR, Snell LS, Cate OT, et al. Competency-based medical education: theory to practice. Med Teach. 2010;32(8):638-645. https://doi.org/10.3109 /0142159X.2010.501190

3. Lucey CR, Thibault GE, Ten Cate O. Competency-based, tme-variable 
education in the health professions: crossroads. Acad Med. 2018;93(3S Competency-Based, Time-Variable Education in the Health Professions):S1-S5. https://doi.org/10.1097/ACM.0000000000002080

4. Custers EJFM, Ten Cate $O$. The history of medical education in Europe and the United States, with respect to time and proficiency. Acad Med. 2018;93(3S Competency-Based, Time-Variable Education in the Health Professions):S49-S54. https://doi.org/10.1097/ACM.0000000000002079

5. Barr DA. Revolution or evolution? Putting the Flexner Report in context. Med Educ. 2011;45(1):17-22. https://doi.org/10.1111/j.1365-2923.2010.03850.x

6. Association of American Medical Colleges. Minutes of the Fifteenth Annual Meeting. April 10, 1905; Chicago, IL.

7. Bevan A. Council on Medical Education of the American Medical Association. JAMA. 1907;48(20):1701-1707.

8. Flexner A. Medical education in the United States and Canada. From the Carnegie Foundation for the Advancement of Teaching, Bulletin Number Four, 1910. Bull World Health Organ. 2002;80(7):594-602.

9. McGaghie WC, Sajid AW, Miller GE, et al. Competency-based curriculum development in medical education: an introduction. Public Health Pap. 1978;(68):11-91.

10. Frank JR, Snell L, Englander R, Holmboe ES, ICBME Collaborators. Implementing competency-based medical education: moving forward. Med Teach. 2017;39(6):568-573. https://doi.org/10.1080/0142159X.2017.1315069

11. Schumacher DJ, West DC, Schwartz A, et al. Longitudinal assessment of resident performance using entrustable professional activities. JAMA Netw Open. 2020;3(1):e1919316. https://doi.org/10.1001/jamanetworkopen .2019 .19316

12. Warm EJ, Held J, Hellman M, et al. Entrusting observable practice activities and milestones over the 36 months of an internal medicine residency. Acad Med. 2016;91(10):1398-1405. https://doi.org/10.1097 /ACM.0000000000001292

13. Jason H. Effective medical instruction: requirements and possibilities. In: Pro- ceedings of a 1969 International Symposium on Medical Education. Medica; 1970:5-8.

14. Andrews JS, Bale JF Jr, Soep JB, et al. Education in Pediatrics Across the Continuum (EPAC): first steps toward realizing the dream of competency-based education. Acad Med. 2018;93(3):414-420. https://doi.org/10.1097 /ACM.0000000000002020

15. Mejicano GC, Bumsted TN. Describing the journey and lessons learned implementing a competency-based, time-variable undergraduate medical education curriculum. Acad Med. 2018;93(3S Competency-Based, Time-Variable Education in the Health Professions):S42-S48. https://doi.org/10.1097 /ACM.0000000000002068

16. Goldhamer MEJ, Pusic MV, Co JPT, Weinstein DF. Can COVID catalyze an educational transformation? Competency-based advancement in a crisis. N Engl J Med. 2020;383(11):1003-1005. https://doi.org/10.1056 /NEJMp2018570

17. Murray KE, Lane JL, Carraccio $C$, et al. Crossing the gap: using competency-based assessment to determine whether learners are ready for the undergraduate-to-graduate transition. Acad Med. 2019;94(3):338-345. https:// doi.org/10.1097/ACM.0000000000002535

18. Schwartz A, Balmer DF, Borman-Shoap E, et al. Shared mental models among clinical competency committees in the context of time-variable, competency-based advancement to residency. Acad Med. 2020;95(11S Association of American Medical Colleges Learn Serve Lead: Proceedings of the 59th Annual Research in Medical Education Presentations):S95-S102. https:// doi.org/10.1097/ACM.0000000000003638

19. Kotter JP. Leading change: why transformation efforts fail. Harvard Business Review. May-June 1995. Accessed March 1, 2021. https://hbr.org/1995/05 /leading-change-why-transformation-efforts-fail-2

20. Schumacher DJ, Caretta-Weyer H, Busari J, et al. Competency-based time-variable training internationally: ensuring practical next steps. Med Teach. Forthcoming. 